\title{
建筑工程土建施工中桩基础技术的应用研究
}

\author{
王鹏飞 \\ 中国电子系统工程第二建设有限公司，江苏 无锡 214000
}

[摘要] 我国建筑行业正处于快速发展的阶段，出现了各种先进的施工技术。不过因为经济发展的不平衡，我国的东北以及西 部的建筑市场发展空间还是很大的。施工质量以及效率的提升是建筑行业能够持续发展的基础。桩基础技术就是一项非常重 要的施工技术, 对于建筑行业的发展同样有很大的影响。建筑施工时为避免地基不合理, 发生地质灾害时稳定性不足, 就需 用运用桩基础技术对其进行加固，提高地基的稳固性。桩基础技术是建筑工程土建施工经常会运用的一种技术，对于提高建 筑的质量有着重要的作用。

[关键词]建筑工程; 土建施工; 桩基施工; 技术要点

DOI: $10.33142 /$ ec.v3i4.1753 中图分类号: TU753.3 文献标识码：A

\section{Application of Pile Foundation Technology in Civil Engineering Construction}

\author{
WANG Pengfei
}

China Electronics System Engineering No.2 Construction Co., Ltd., Wuxi, Jiangsu, 214000, China

\begin{abstract}
Chinese construction industry is in the stage of rapid development and there are various advanced construction technologies. However, due to the imbalance of economic development, the development space of construction market in Northeast and West China is still very large. The improvement of construction quality and efficiency is the basis for the sustainable development of construction industry. Pile foundation technology is a very important construction technology, which also has a great impact on the development of construction industry. In order to avoid unreasonable foundation and insufficient stability in case of geological disaster during construction, pile foundation technology should be used to reinforce the foundation and improve the stability of the foundation. Pile foundation technology is often used in civil engineering construction, which plays an important role in improving quality of buildings. Keywords: construction engineering; civil construction; pile foundation construction; technical points
\end{abstract}

\section{引言}

对于建筑工程来说桩基施工是非常重要的一个环节, 对于上部结构的时候以及使用都会有很大的影响。所以, 一 定要加强对于桩基础施工的控制, 把握好施工的技术要点。

1 土建施工中桩基础技术概述

1.1 桩基础技术

我国正处于快速的发展之中, 出现了很多的新技术、新材料以及新工艺, 这也给建筑施工带来了很大的变化, 而 桩基础技术就是对于土建施工来说意义非常重大的一项技术。其中包含基桩和顶桩的承台互相结合，主要底层台桩基 与高层台桩基两种, 后者又有预制桩与灌注桩两种形式, 这两种都是使用最多的桩基础技术。利用桩基础技术能够将 来自不同方向的承载力都转移到涂层周围去, 这样就能够为上层建筑提供更稳定的负荷, 在遭受自然灾害的时候也就 能够体现出更强的抵御能力，将外界带来的压力通过桩基传递到土层中去，减少灾害对于建筑造成的破坏。

\section{2 桩基础技术的主要作用}

随着技术的进步, 建筑的规模在不断扩大, 超高层建筑的数量也越来越多, 这些都要求桩基础要有更好的承载力, 而桩基技术的应用正是提升建筑物基础承载力、加固地基的有效手段，对于避免出现建筑物倒塌的情况有着非常显著 的作用。因为桩基技术的作用建筑的地基更加牢固，建筑物的整体质量也能有很大的提升，对于建筑行业的发展是非 常有意义的。

\section{3 桩基础技术实际的施工需求}

在进行桩基础施工的时候, 一定要充分的考虑地基的变形以及承载力。工作人员必须要到施工现场进行实地勘察, 了解当地的地质水文方面的信息。桩基础施工技术性要求很高, 对于施工现场、桩基础也同样有着特殊的要求。所以, 一定要做好市场现场的调查工作, 真正的了解了现场的环境情况以后, 才能开展桩基础的设计与施工, 这样才能发挥 桩基础的作用，为建筑提供足够的承载力。

1.4 桩基础技术施工的优势

进行桩基础施工能力提高支撑层桩的承载力, 防止出现高层的垂直荷载, 大大的降低了整体的荷载, 能够有效的 
预防地基沉降问题的出现, 是整个建筑的承载力都有大幅度的提升。桩基础技术施工还能够有效的避免地基周围发生 变形，这个特性也进一步提升了桩基技术在土建施工中的作用。一是桩基础技术会对桩基桩位的黏土、石块等进行科 学的处理, 从而提升基础的稳定性, 这样在出现外力作用时建筑才不会容易出现圾塌问题。二是桩基础技术会作用在 地层上。这样, 如果因为地震等地质灾害的发生使得地面出现沉降的话, 桩基也能够为建筑提供足够的支撑力, 从而 将灾害的影响降到最低 ${ }^{[1]}$ 。

\section{2 土建施工过程中桩基础施工条件}

桩基础在土建施工中的作用是冊庸置疑的, 不过相对于其他的一些普通地基施工项目来说, 桩基础施工的工程量 更大, 施工成本也会更高。同时, 桩基础技术本身也是有着一定的使用条件的, 并不能适用所有的建筑类型或者所有 规模的建筑。所以, 如果想要采用桩基础施工技术的话, 应该要看看是否具备以下的这些条件。一、对于地基质量有 什么样的要求, 一般如果要求比较高的话则适用桩基础施工技术。二、建筑对于承载力的要求如何, 如仓库等要求有 比较高的承载力的基础的话就则适用桩基础施工技术。三、面积小但是高度比较高, 自身重力也很大的建筑, 如烟图 等适用于桩基础技术。四、如精密仪表制造场所等要求有很高的稳定性的建筑适用于桩基础技术。五、一些特殊地基 区域, 比如说软土地基应采用桩基础技术。六、地震带的建筑有必要运用桩基础技术 ${ }^{[2]}$ 。

\section{3 建筑工程土建施工中桩基础施工技术的应用分析}

\section{1 土建施工准备阶段}

土建施工做好各项准备工作, 要对施工地区进行现场勘查和检测, 有了准确、详细的数据以后才能制定相应的施 工技术以及方案, 并根据这些信息确定桩的位置以及数量等。一是要到施工现场进行勘测、检查, 全面的分析当地的 地质水文情况。二是要根据勘测、收集的相关信息来制定施工方案, 然后在编制施工编制单, 确定相应的施工参数等。 三是必须要重视桩基的防线定位工作, 这道工序的质量对于每个水准点是否有效有着直接的影响, 同时也是保证桩基 标高精度的依据, 同时, 施工单位一定要准确、详细的记录桩基底部和顶部的信息 ${ }^{[3]}$ 。

\section{2 振动沉桩施工技术应用}

在应用这一技术的时候, 首先要在桩基的底部按上振动设备, 通过振动是的桩体落入到地基的制定位置, 对于桩基 施工质量的提升有着积极的作用。桩基振动设备通常的结构都是很简单的, 大多数的工程施工都会利用到, 不过这种设 备的应用也有一定的缺陷, 其中噪音比较大就是一个比较严重的问题, 如果是在城区的话, 就需要采取一定的措施。

\section{3 钻孔灌注桩施工技术应用}

桩基础施工技术最常见的就是泥浆护壁钻孔灌注桩施工技术, 通过机械进行钻孔然后灌浆, 在进行施工的时候对 于周围结构或者土层就可能产生比较大的破坏影响, 为了避免这种情况的发生就要利用泥浆使孔壁变得稳定, 碎石也 会随着泥浆被排出来, 在经过清洗并装入钢筋后就可以灌入混凝土。一般沙土、碎石土地质使用这种技术会有比较好 的效果。不过该技术有着很高的技术要求，施工过程中也复杂，对于混凝土的消耗也会比较多，成本也会比较高。

\section{4 静力压桩施工技术}

如今环保已经成为了人们的共识，建筑行业同样也开始渗透绿色、环保的理念，而静压桩技术就是为了满足环保 方面的要求而开发出来的, 它的基本特点就是震动弱而噪音比较小, 这样就不容易产生噪音污染, 对周围环境的影响 也比较小。这种技术首先需用通过压装模板形成静压力, 然后以此将桩压入地基, 在开始打桩之前要利用抽线将位置 标记出来, 桩心也要利用钢筋做出标记 ${ }^{[4]}$ 。

\section{5 预制桩技术}

在建筑工程土建桩基础施工中, 预制桩技术应用时需要注意以下几个方面: (1)桩尖的朝向问题。通常情况下, 桩 尖的朝向应该根据打桩的顺序来决定; (2)预制桩浇筑的顺序。为了保障浇筑施工的效果, 预制桩通常是从顶端开始浇 筑。预制桩是振动沉桩和静力压桩的主要作业目。在具体施工的过程中, 采取人工挖掘的方式将桩打至标准位置。这 种方法在大部分土质的土壤中都适用, 其优点在于可以将桩基础施工对周边环境造成的负面影响控制到最低。在可持 续发展理念的影响下，人工挖孔施工技术已经成为建筑工程土建桩基础施工中最常用的技术之一 ${ }^{[5]}$ 。

\section{4 结束语}

综上所述, 桩基施工技术在当前建筑工程中的应用越来越多, 尤其是高层与超高层建筑, 把控好相关技术要点, 是保证桩基施工质量, 达到预期效果的关键所在。

\section{[参考文献]}

[1]陆强.建筑工程土建施工中桩基础技术要点研究 [J].建材与装饰, 2020 (05) : 11-12.

[2]周辉. 建筑工程土建施工中桩基础技术的应用 [J]. 住宅与房地产, 2020(03): 207.

[3]刘国柱. 建筑工程土建施工中桩基础技术的应用研究 [J]. 居业,2020(01): 114-116.

[4] 韩存义. 建筑工程土建施工中桩基础技术要点 [J]. 建材与装饰, 2019(35): 6-7.

[5]李明星.建筑工程土建施工中桩基础技术的应用研究 [J]. 建材与装饰, 2019(35): 27-28.

作者简介: 王鹏飞（1990.11.20-), 男, 佳木斯大学, 土木工程, 中国电子系统工程第二建设有限公司。 